International Journal of Agriculture, Environment and Bioresearch

Vol. 5, No. 03; 2020

ISSN: $2456-8643$

\title{
TRICHODERMA HARZIANUM AND BACTERIAL STRAINS AS BIOAGENTS FOR SUPPRESSING OROBANCHE CRENATA GROWTH AND PARASITISM IN FABA BEAN
}

\author{
Yahia, M.Y.A. ${ }^{1}$; Hassan, M.M. ${ }^{2}$; Elamin, M.A. ${ }^{1}$; Abdalla, N.K. ${ }^{3}$; Rugheim, A.M.E. ${ }^{1}$; Osman, A.G. ${ }^{2}$;Abdelgani, \\ M.E. ${ }^{2}$ and Babiker, A.G.T. ${ }^{2}$ \\ ${ }^{1}$ Faculty of Agriculture, Omdurman Islamic University, Omdurman, Sudan \\ ${ }^{2}$ Bio-pesticides and Bio-fertilizers Department, Environment, Natural Resources and Desertification Research \\ Institute, National Centre for Research, Khartoum, Sudan \\ ${ }^{3}$ Shendi Research Station, Agriculture Research Corporation, Shendi, Sudan
}

https://doi.org/10.35410/IJAEB.2020.5502

\begin{abstract}
A series of field, laboratory and greenhouse experiments were conducted at the Bio-pesticides and Bio-fertilizers Department, Environment, Natural Resources and Desertification Research Institute (ENDRI), National Centre for Research (NCR), Khartoum, Sudan and College of Agricultural Studies, Sudan University of Science and Technology at Shambat, Khartoum North Sudan to study the effects of Trichoderma harzianum, herbicide imazethapyr, Bacillus megatherium var. phosphaticum (BMP) and Rhizobium leguminosarum biovar viceae strain (TAL1399) on $O$. crenata germination, incidence and faba bean growth, nodules number and plant height. Results of germination experiment showed that application of GR24 to O. crenata seeds conditioned in water induced germination to $80 \%$. Application of $T$. harzianum significantly reduced $O$. crenata germination by $82 \%$ compared to control. The combination BMP + TAL1399 significantly reduced $O$. crenata germination by $32-42 \%$ as compared to control. Destructive sample experiment results showed that T. harzianum alone gave the highest nodules number and nodules dry weight compared to the control and the herbicide. The bacterial strains BMP and TAL1399 each alone or in combination significantly increased nodules number and dry weight as compared to the control. Extract of nodules collected from roots treated with T. harzianum and imazethapyr each alone or in combination, BMP and TAL1399 each alone or in combination significantly decreased $O$. crenata seed germination as compared to the control. Greenhouse results showed that $T$. harzianum and imazethapyr alone or in combination significantly decreased nodules numbers and $O$. crenata numbers as compared to the infected control and significantly increased faba bean biomass and plant height as compared to control. BMP, TAL1399 each alone or in combination significantly increased plant height, faba bean biomass and nodules numbers and decreased $O$. crenata number as compared to the infested control.
\end{abstract}

Keywords: BMP, Broomrape, Imazethapyr, Rhizobium, Trichoderma.

\section{INTRODUCTION}

Orobanche spp. are root parasitic flowering plants devoid of chlorophyll that cause important yield losses in several crops especially in food and feed legumes. Orobanche crenata is a 
Vol. 5, No. 03; 2020

ISSN: $2456-8643$

holoparasite causes significant damage to the culture of leguminous plants particularly faba bean (Vicia faba L.). An intensive hyphal branching in response to host recognition can be induced by a group of chemicals called "strigolactones" (SLs) that are released from plant roots. 5Deoxystrigol was the first SL isolated as a branching factor from root exudates of Lotus japonicus (Akiyama et al., 2005).

The structures of orobanchol and orobanchyl acetate have been revised recently as shown by (Ueno et al., 2011). To date, most research regarding acquisition by plants has been focused on the association of legume root nodules with bacteria, whereas the importance of arbuscular mycorrhizal (AM) fungus-plant symbiosis has been mainly remarked on in the context of phosphorus uptake. However, AM fungi supply nitrogen as well as phosphorus to host plants (Ames et al., 1983; Johansen et al., 1996). Trichoderma spp. are free-living fungi commonly widespread in soil and root ecosystems. Root colonization frequently results in enhancing of growth and development, crop productivity or induction of resistance to abiotic and biotic factors (Hohmann et al., 2011). Guzm'an-Guzm'an et al. (2018) reported that the mechanisms employed by Trichoderma include secretion of effector molecules and secondary metabolites that mediate the beneficial interaction of Trichoderma with plants, providing tolerance to biotic and abiotic stresses. The objective of this study is developing a control method for $O$. crenata using soil born fungi and bacteria and herbicide imazethapyr.

\section{MATERIALS AND METHODS}

Series of field, greenhouse and laboratory experiments were conducted at the Bio-pesticides and Bio-fertilizers Department, Environment, Natural Resources and Desertification Research Institute (ENDRI), National Centre for Research (NCR), Khartoum, Sudan. The field experiments were conducted at the College of Agricultural Studies, Sudan University of Science and Technology at Shambat, Khartoum North, Sudan during November to January, 2017/18. Seeds of the faba bean cultivars cv: BB7 was obtained from Shendi Research Station, Agricultural Research Corporation, River Nile State, Sudan. Greenhouse experiments were conducted at the greenhouse, Faculty of Agriculture, Omdurman Islamic University, to study the effects of Trichoderma harzianum, herbicide imazethapyr, Bacillus megatherium var. phosphaticum (BMP) and Rhizobium leguminosarum strain (TAL1399) on O. crenata germination, and faba bean growth, nodules number and plant height. The strigolactone analogue synthetic stimulant (GR24) was provided by professor Zwanenberg, University of Nimijhen, the Netherlands. A stock (10 ppm) of GR24 was prepared by dissolving $1 \mathrm{mg}$ in $1 \mathrm{ml}$ acetone and completing to volume $(100 \mathrm{ml})$ with sterile distilled water. The solution was kept in refrigerated at $4^{\circ} \mathrm{C}$ for further use.

\section{Laboratory experiments}

Collection of treated faba bean nodules: Seeds of the faba bean cultivars BB:7 were obtained from the (ARC), Shendi Research Station. Seeds were sown and treated with treatments mentioned above, at the farm of College of Agricultural Studies, Sudan University of Science and Technology at Shambat during November to January, 2017/2018. The nodules were collected at 40, 50 and 60 days after sowing.

Faba bean nodules (1g each) were crushed in $10 \mathrm{ml}$ of sterilized distilled water in a mortar. The nodules extract, filtered through Whatman No. 1 filter paper, was kept in a refrigerated at $5^{\circ} \mathrm{C}$. 
Effect of nodules extract on $O$. crenata germination in response to GR24 during conditioning: $O$. crenata seeds were conditioned in water for 11 days were treated with nodules extracts. Seeds were dapped on normal filter paper (No. 1) to remove excess water and then transferred to sterile Petri dishes. Each disc was treated with diluted filtrate of nodules extracts $(30 \mu \mathrm{l})$ GR24 $(10 \mathrm{ppm})$. Then seeds were re-incubated and examined for germination. Then seeds were re-incubated and examined for germination.

Greenhouse experiment: Greenhouse experiments were conducted at the greenhouse, Faculty of Agriculture, Omdurman Islamic University, during December, 2018 to March, 2019, to study the effects of T. harzianum, herbicide imazethapyr, BMP, TAL1399 Bacterial and combinations on $O$. crenata in faba bean. A soil mixture was made of sandy-loam soil and sand $(1: 1 \mathrm{v} / \mathrm{v})$, then $7 \mathrm{~kg}$ were placed in pots $(20 \mathrm{~cm}$ diameter $) . O$. crenata infested and un-infested controls were included for comparison. O. crenata infestation was accomplished by mixing $5 \mathrm{mg}$ of sterilized broomrape seeds in the soil in each pot. Three faba bean seeds were sown per pot. Seventeen days after sowing, plants were thinned to one plant per pot and the pots were irrigated twice every week. Experiments were terminated when the host plants in the control treatments stopped growing due to $O$. crenata infection. Numbers of $O$. crenata shoots emerged per pot were recorded at $8,9,10,11$ and 12 weeks after sowing (WAS). Faba bean plant height and dry weight of faba bean shoots and roots were recorded at the end of the experiment.

Statistical analysis: Data collected from laboratory and field experiments were subjected to statistical analysis (ANOVA), using SPSS 22 statistical package and means were separated for significance using the (DMRT) at $\mathrm{P} \leq 0.05$.

\section{RESULTS}

\section{Laboratory experiments}

\section{Effect of $\boldsymbol{T}$. harzianum and bacterial strains on $\boldsymbol{O}$. crenata seeds germination}

Results in table (1) showed that application of GR24 at 10 and 5ppm to O. crenata seeds conditioned in water induced germination by $69 \%$ and $82 \%$ respectively. Application of all $T$. harzianum densities gave the highest significant $(\mathrm{P} \leq 0.05)$ inhibition on $O$. crenata germination. It reduced germination by $82-62 \%$ compared to both controls. Application of the bacterial strains combination BMP + TAL1399 significantly $(\mathrm{P} \leq 0.05)$ reduced germination by $31-42.47 \%$ as compared to the control.

Table 1 Effects of treatments on $\boldsymbol{O}$. crenata germination

\begin{tabular}{|l|l|l|}
\hline \multirow{2}{*}{ Treatments } & \multicolumn{2}{|l|}{ Germination (\%) } \\
\cline { 2 - 3 } & GR24 10ppm & GR24 5ppm \\
\hline Water & $80.21^{\mathrm{d}}$ & $69.73^{\mathrm{e}}$ \\
\hline Medium & $77.45^{\mathrm{d}}$ & $70.42^{\mathrm{e}}$ \\
\hline T. harzianum & $13.41^{\mathrm{a}}$ & $8.63^{\mathrm{a}}$ \\
\hline
\end{tabular}




\begin{tabular}{|l|l|l|}
\hline $1 / 2$ T. harzianum & $14.31^{\mathrm{a}}$ & $13.53^{\mathrm{ab}}$ \\
\hline $1 / 3$ T. harzianum & $28.92^{\mathrm{b}}$ & $27.76^{\mathrm{bc}}$ \\
\hline $1 / 4$ T. harzianum & $29.25^{\mathrm{b}}$ & $26.46^{\mathrm{bc}}$ \\
\hline BMP + TAL1399 & $48.55^{\mathrm{c}}$ & $46.46^{\mathrm{d}}$ \\
\hline $1 / 2$ BMP + TAL1399 & $50.69^{\mathrm{c}}$ & $40.44^{\mathrm{cd}}$ \\
\hline $1 / 3$ BMP + TAL1399 & $57.14^{\mathrm{c}}$ & $49.64^{\mathrm{d}}$ \\
\hline $1 / 4$ BMP + TAL1399 & $55.29^{\mathrm{c}}$ & $53.52^{\mathrm{d}}$ \\
\hline $\mathrm{p} \leq 0.05$ & $* *$ & $* *$ \\
\hline $\mathrm{SE} \pm$ & 4.29 & 3.90 \\
\hline SD \pm & 22.30 & 20.27 \\
\hline
\end{tabular}

Means followed by the same letter(s) are not significantly different according to DMRT at $\mathrm{P} \leq 0.05$. According to LSD test. ${ }^{* *}=\mathrm{p} \leq 0.01$

Effects of faba bean nodules extract on $\boldsymbol{O}$. crenata seeds germination in response to GR24, T. harzianum +Imazethapyr

Results in figures (Fig.1,2 and 3) showed that application of GR24 at 10 and 5ppm to O. crenata seeds conditioned in water induced germination by $91.48-77.56 \%$. Application of nodules extract collected at 40 DAS from all treatments decreased seeds germination of $O$. crenata during conditioning as compared to the control. The low concentration of all treatments gave the higher germination compared to the high concentration (Fig.1). Extract of nodules collected at 50 DAS and treated with $T$. harzianum and imazethapyr each alone or in combination decreased $O$. crenata seeds germination (Fig.2). Extract of nodules treated with $T$. harzianum, imazethapyr each alone or in combination and collected at 60 DAS decreased seed germination of broomrape compared to the control (Fig.3).

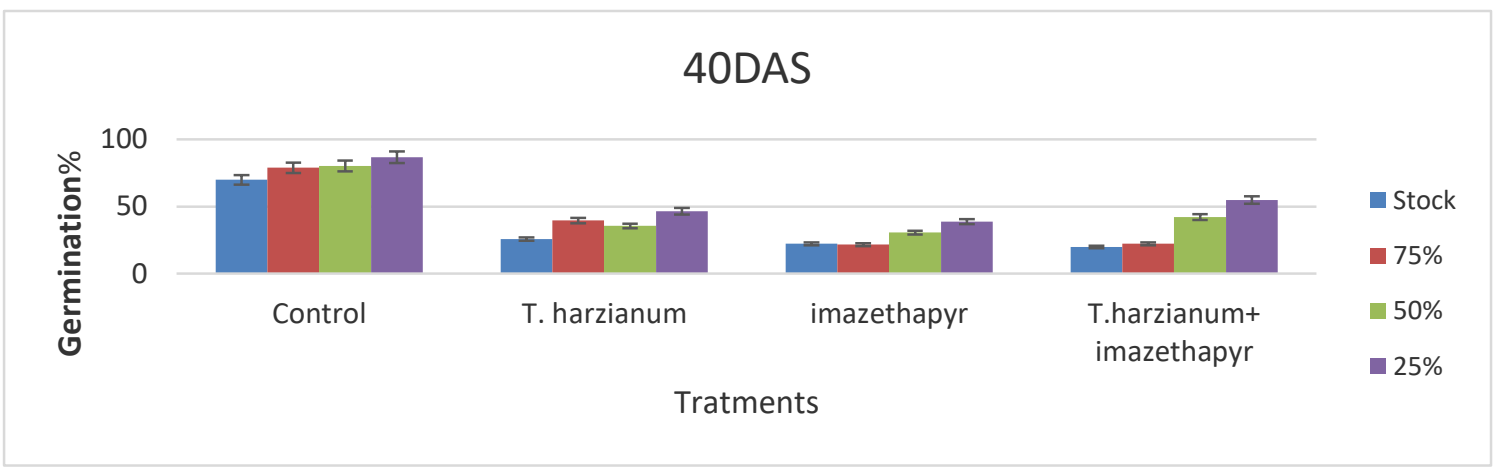

Fig. 1 Effects of nodules extract (collected at 40 DAS) on $O$. crenata seeds germination in response to GR24 (during conditioning) as T. harzianum +Imazethapyr 


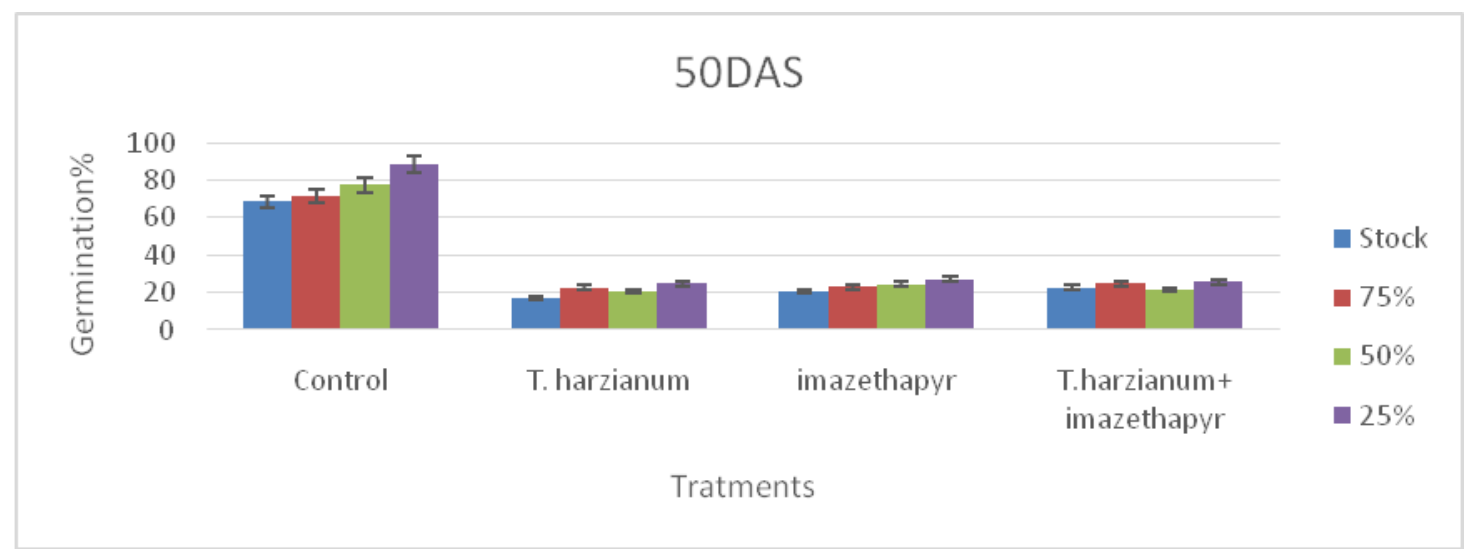

Fig. 2 Effects of nodules extract (collected at 50 DAS) on $O$. crenata seeds germination in response to GR24 (during conditioning) as T. harzianum +Imazethapyr

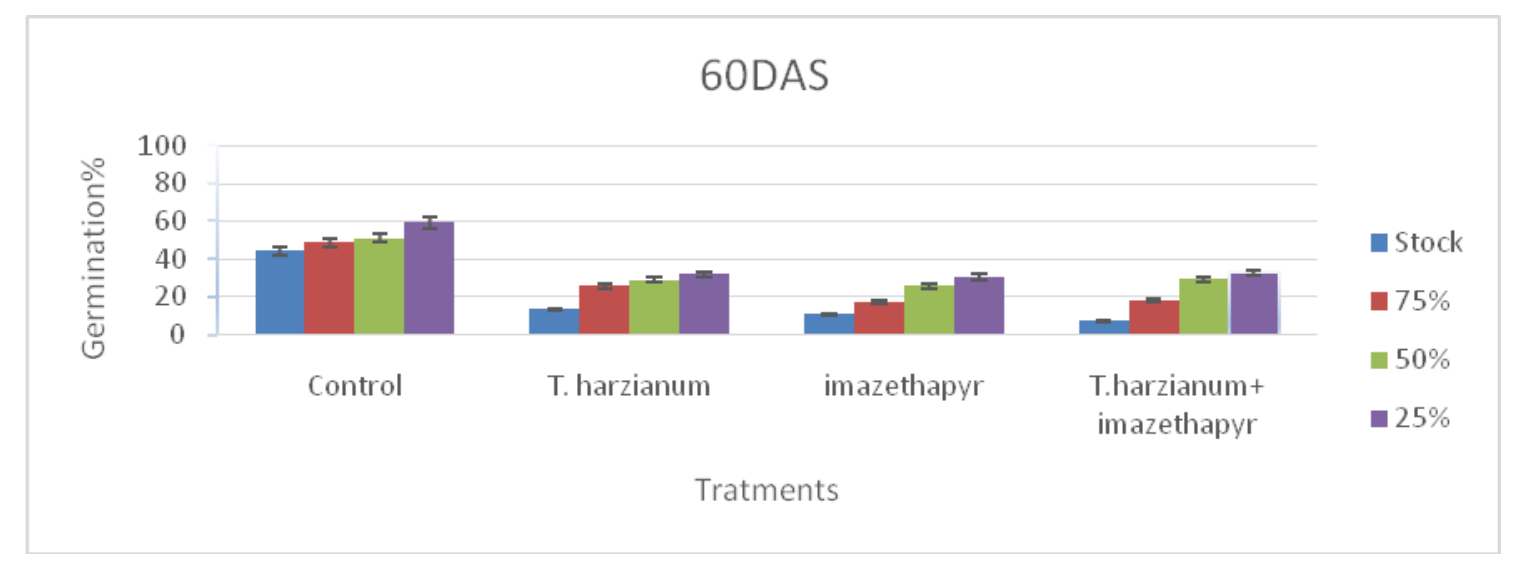

Fig. 3 Effects of nodules extract (collected at 60 DAS) on $O$. crenata seeds germination in response to GR24 (during conditioning) as T. harzianum +Imazethapyr

Effects of faba bean nodules extract on $O$. crenata seeds germination in response to GR24, bacterial strains

Results in figure4, 5 and 6 showed that application of GR24 at 10 and 5 ppm to $O$. crenata seeds conditioned in water induced germination by a rage (91.48 - 77.56\%). Application of nodules extract collected at 40 DAS from all treatments decreased $O$. crenata seeds germination during conditioning compared to the control, the higher extract concentration gave less germination percentage compared the low concentration (Fig.4). The highest extract concentration of nodules treated with BMP and TAL1399 each alone or in combination and collected at 60 DAS decreased $O$. crenata seed germination as compared to the control (Fig.6). 
Vol. 5, No. 03; 2020

ISSN: $2456-8643$

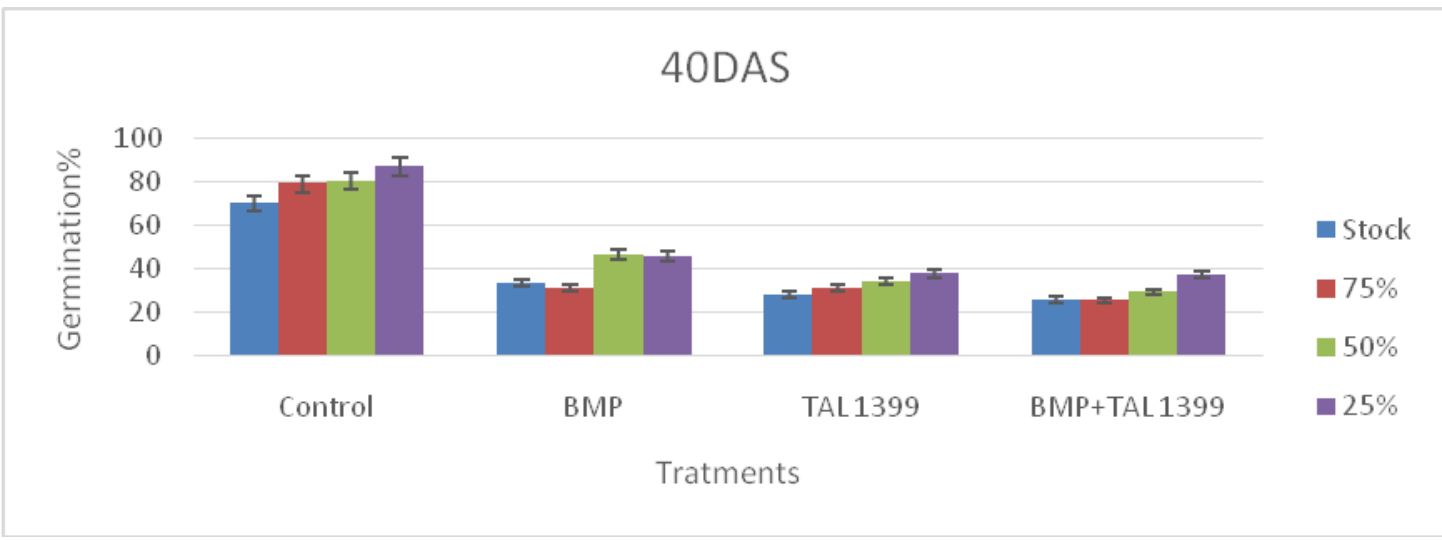

Fig.4 Effects of nodules extract (collected at 40 DAS) on $O$. crenata seeds germination in response to GR24 (during conditioning) as bacterial strains

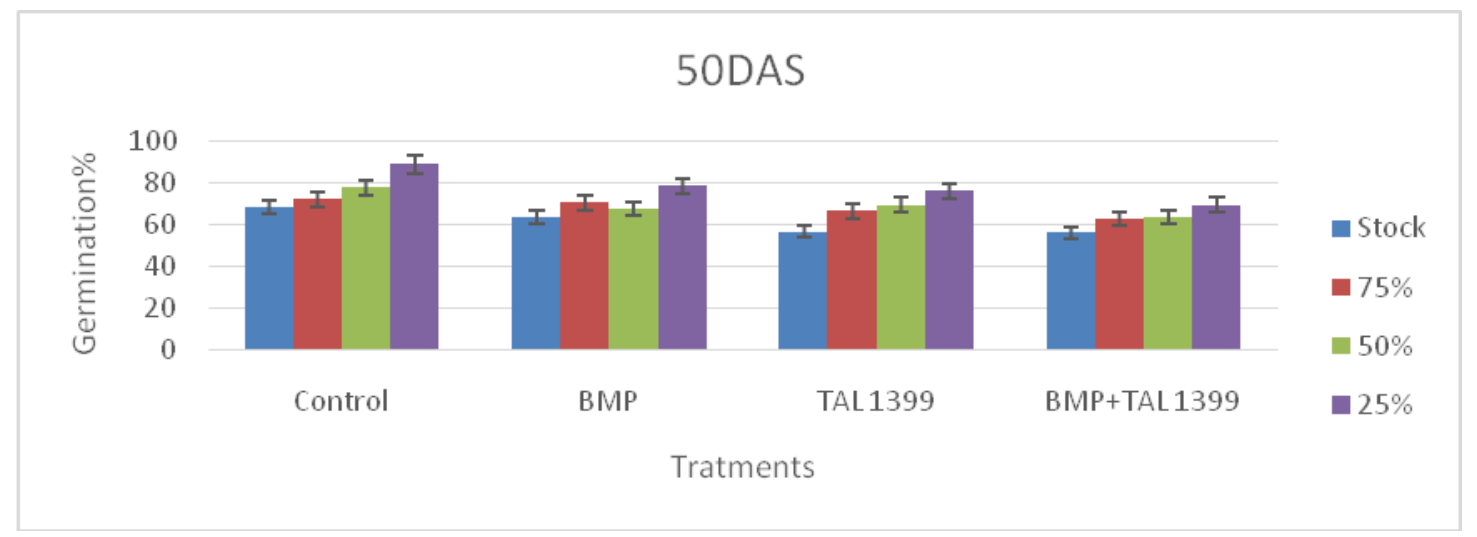

Fig.5 Effects of nodules extract (collected at 50 DAS) on $O$. crenata seeds germination in response to GR24 (during conditioning) as bacterial strains

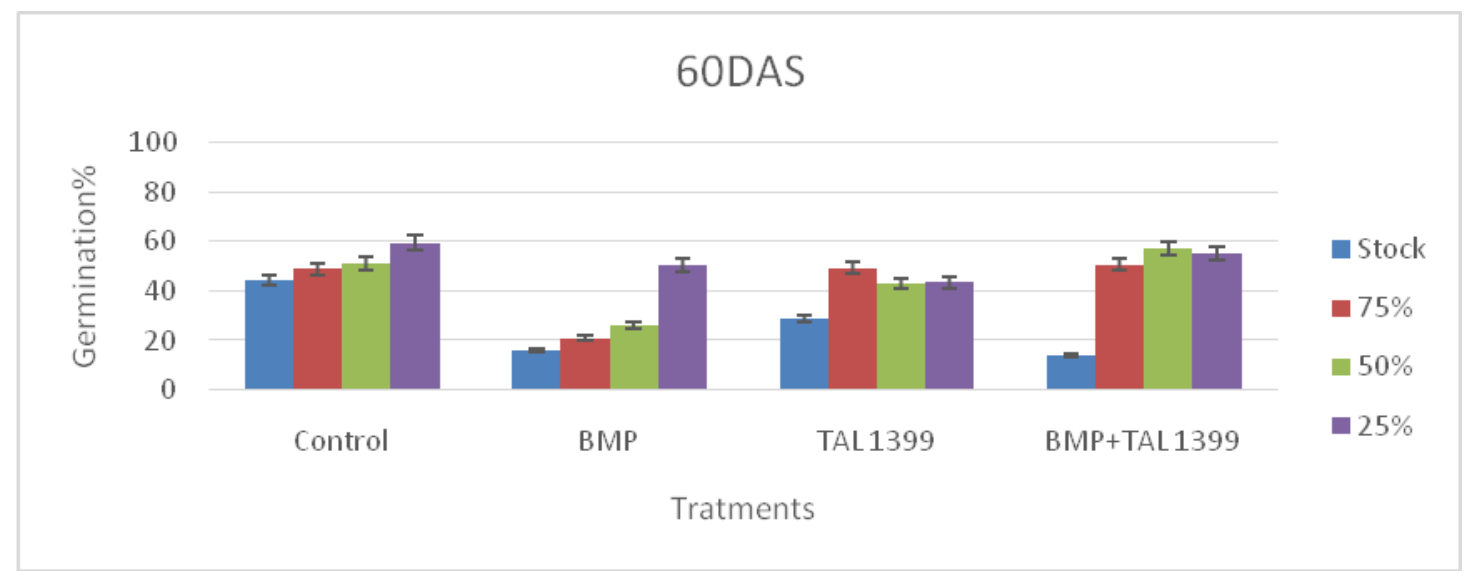

Fig.6 Effects of nodules extract (collected at 60 DAS) on $O$. crenata seeds germination in response to GR24 (during conditioning) as bacterial strains 


\section{Greenhouse experiments}

Effects of $\boldsymbol{T}$. harzianum and imazethapyr on faba bean growth and $O$. crenata development

Results of the experiment showed that plant height increased with all treatments compared to the infected control. T. harzianum and uninfected control gave the highest plant height (33-35) (Table 2). T. harzianum and imazethapyr alone or in combination significantly $(\mathrm{P} \leq 0.05)$ decreased nodules numbers (Table.6) and $O$. crenata numbers as compared to the infected control (85-86.6) (Table 3). T. harzianum + imazethapyr significantly $(\mathrm{P} \leq 0.05)$ increased faba bean biomass as compared to the control with $O$. crenata (Table 4).

Table 2. Effects of T. harzianum and imazethapyr on faba bean plant height

\begin{tabular}{|l|l|l|l|}
\hline \multirow{2}{*}{ Treatments } & \multicolumn{3}{l|}{ Plant height (cm) } \\
\cline { 2 - 4 } & 60 DAS & $\mathbf{7 0}$ DAS & 80 DAS \\
\hline Control without O. crenata & 31.33 & 33.83 & 34.83 \\
\hline Control with O. crenata & 33.67 & 31.83 & 24.00 \\
\hline T. harzianum & 31.50 & 34.75 & 35.33 \\
\hline T. harzianum+ Imazethapyr & 26.33 & 28.33 & 33.33 \\
\hline Imazethapyr & 25.00 & 26.33 & 26.67 \\
\hline SE \pm & 0.20 & 0.20 & 1.09 \\
\hline SD \pm & 0.92 & 0.91 & 5.34 \\
\hline
\end{tabular}

Table3. Effects of $T$. harzianum and imazethapyr on nodules number and faba bean biomass

\begin{tabular}{|l|l|l|}
\hline Treatments & Nodules number/plant & Faba bean biomass \\
\hline Control without O. crenata & 12.00 & 5.67 \\
\hline Control with O. crenata & 11.00 & 2.67 \\
\hline$T$. harzianum & 8.67 & 5.33 \\
\hline$T$. harzianum+ Imazethapyr & 7.67 & 6.67 \\
\hline Imazethapyr & 5.33 & 4.00 \\
\hline $\mathrm{SE} \pm$ & 0.95 & 0.42 \\
\hline $\mathrm{SD} \pm$ & 4.67 & 2.05 \\
\hline
\end{tabular}


Table 4. Effects of $T$. harzianum and imazethapyr on $O$. crenata number/pot

\begin{tabular}{|l|l|l|}
\hline \multicolumn{1}{|c|}{ Treatments } & \multicolumn{2}{|l|}{ O. crenata No/pot } \\
\cline { 2 - 3 } & 70 DAS & 80 DAS \\
\hline Control with $O$. crenata & $2.17^{*}(5.00)^{* *}$ & $2.57(6.67)$ \\
\hline T. harzianum & $0.47(0.67)$ & $0.80(1.00)$ \\
\hline T. harzianum+ Imazethapyr & $1.14(2.00)$ & $1.62(3.00)$ \\
\hline Imazethapyr & $0.91(1.33)$ & $1.24(2.33)$ \\
\hline $\mathrm{SE} \pm$ & 0.28 & 0.27 \\
\hline $\mathrm{SD} \pm$ & 0.98 & 0.94 \\
\hline
\end{tabular}

*Data out of brackets are square root transformed for analysis

** Data between brackets are original data.

Effect of bacterial strains BMP and TAL1399 on faba bean growth and $O$. crenata development

The BMP+TAL1399 and unifected control gave the highest plant height at 80DAS (Table 5). The BMP and TAL1399 alone or combination increased nodules number, decreased $O$. crenata number and significantly $(\mathrm{P} \leq 0.05)$ increased faba bean biomass as compared to the infected control (Tables 6 and 7).

Table 5. Effect of bacterial strains BMP and TAL1399 on faba bean plant height

\begin{tabular}{|l|l|l|l|}
\hline \multirow{2}{*}{ Treatments } & \multicolumn{3}{l|}{ Plant height (cm) } \\
\cline { 2 - 4 } & 60DAS & 70DAS & 80DAS \\
\hline Control without $O$. crenata & 31.33 & 33.83 & 34.83 \\
\hline Control with $O$. crenata & 25.67 & 26.00 & 32.08 \\
\hline BMP & 26.33 & 27.67 & 34.00 \\
\hline TAL1399 & 28.33 & 29.83 & 33.33 \\
\hline BMP+ TAL1399 & 25.67 & 34.00 & 34.33 \\
\hline SE \pm & 0.87 & 1.09 & 1.40 \\
\hline SD \pm & 3.03 & 5.34 & 4.83 \\
\hline
\end{tabular}


International Journal of Agriculture, Environment and Bioresearch

Vol. 5, No. 03; 2020

ISSN: $2456-8643$

Table 6.Effect of bacterial strains BMP and TAL1399 on nodules number and faba bean biomass

\begin{tabular}{|l|l|l|}
\hline Treatments & Nodules number/plant & Faba bean biomass \\
\hline Control without O. crenata & 12.00 & 5.67 \\
\hline Control with O. crenata & 11.00 & 2.67 \\
\hline BMP & 9.67 & 5.67 \\
\hline TAL1399 & 14.67 & 6.00 \\
\hline BMP+ TAL1399 & 14.33 & 5.33 \\
\hline SE \pm & 0.95 & 0.42 \\
\hline SD \pm & 4.67 & 2.05 \\
\hline
\end{tabular}

Table 7. Effect of bacterial strains BMP and TAL1399 on $O$. crenata number/pot

\begin{tabular}{|l|l|l|}
\hline \multirow{2}{*}{ Treatments } & \multicolumn{2}{|l|}{ o. crenata No/pot } \\
\cline { 2 - 3 } & 70 DAS & 80 DAS \\
\hline Control with O. crenata & $2.17^{*}(5.00)^{* *}$ & $2.57(6.67)$ \\
\hline BMP & $0.47(0.67)$ & $0.94(1.33)$ \\
\hline TAL1399 & $0.66(0.67)$ & $0.80(1.00)$ \\
\hline BMP+ TAL1399 & $0.67(1.33)$ & $1.00(1.67)$ \\
\hline SE \pm & 0.29 & 0.29 \\
\hline SD \pm & 1.01 & 0.99 \\
\hline
\end{tabular}

*Data out of brackets are square root transformed for analysis

**Data between brackets are origin data.

\section{DISCUSSION}

The world faces two enormous challenges that can be met, at least in part and at low cost, by making certain changes in agricultural practices. There is need to produce enough food for a growing population in the face of adverse climatic trends. Improving photosynthetic efficiency of crop plants can help meet the challenges. Fortuitously, when crop plants' roots are colonized by certain root-endophytic fungi of the genus Trichoderma, this induces up-regulation of genes and pigments that improve the plants' photosynthesis. 
Seeds conditioned in water or yeast extract mannitol broth medium displayed high germination (69.7-80.2\%) in response to GR24. Seeds treated with nodule extract came up from faba bean plants treated with Trichoderma or bacterial strains showed differential germination. Trichoderma irrespective to their concentrations effected negligible germination in comparison to the corresponding control. The observed reductions in germination, the key phase in development of parasitic weeds, by Trichoderma is in line with several reports on reduction of seed germination and viability by Trichoderma spp. (Abbasher and Babiker, 2012).

In the greenhouse experiments, the parasite, when not checked, reduced faba bean height by 8.57- $45.12 \%$. Trichoderma considerably, improved faba bean height. The lack of significant reduction in dry weight in the Trichoderma inoculated Orobanche free faba bean indicates that, the fungus had no significant adverse effects on faba bean growth and that the fungus has the potentials to ameliorate the depressive effects of the parasite on faba bean growth.

Faba bean dry weight, determined at harvest, indicated the high efficacy and potentials of Trichoderma and bacterial strains, as a bio agent for suppressing Orobanche growth and parasitism. Count results showed that Trichoderma affected considerable reductions in the parasite emergence.

Vinale et al. (2008) reported that effective bio-inoculant should penetrate the roots not only to directly antagonize root pathogens, but also to stimulate plant growth and vigor through various mechanisms such as nutrient mobilization, nitrogen use efficiency, induction of host defence as well as the involvement of growth phytohormones from both plant and fungal origins. Application of T. harzianum, the herbicide and their combinations promoted plant growth and reduced Orobanche infestation.

Trichoderma is not only a good biocontrol agent, but also a general fertility promoter. In the absence of pathogens, application of appropriate Trichoderma formulations (following solarisation and/or preceding fumigation with authorized and environmentally-friendly chemicals) can also serve to promote plant growth and crop precocity, increase fruit production and reduce chemical treatments.

Trichoderma spp. is considered as widely studied fungal agent as microbial bio-control agent in agriculture and are marketed in the form of bio-pesticide, bio-fertilizer, growth promoter and natural resistance inducer.

Louarn et al. (2012) reported that Broomrape seeds are less capable to recognize crop roots colonized by arbuscular mycorrhizal fungi, Rhizobium leguminosarum or Azospirillum brasilense due to change in the composition of the root exudates in colonized.

Karasu et al. (2009) observed that inoculation of chickpea seeds with $R$. ciceri isolate had a significant effect on seed yield, plant height, and number of pods per plant, number of seeds per plant, harvest index and 1000 seed weight. The present study supports the hypothesis that inoculation of roots with bacterial combination or Trichoderma enhances a host defence mechanism in faba bean. A decrease of stimulant production by inoculated faba bean could explain the reduced proportion of parasite germination observed in the presence of inoculated plants. Further research in this area is needed. 
Vol. 5, No. 03; 2020

ISSN: $2456-8643$

\section{REFERENCES}

Abbasher, A.A., Zaroug, M.S.; Zahran, E.B., Sauerborn, J., (2012). Germination, attachment and development of Striga hermonthica (Del.) Benth induced by host and non-host crops. University of Khartoum Journal of Agricultural Sciences 20 (3), 229-242.

Akiyama, K., Matsuzaki, K., Hayashi, H., (2005). Plant sesquiterpenes induce hyphal branching in arbuscular mycorrhizal fungi. Nature, 435, 824-827.

Ames, R.N., Reid, C.P.P., Porter, L.K., Cambardellam, C., (1983). Hyphal uptake and transport of nitrogen from two N15 labelled sources by Glomus mosseae, a vesicular-arbuscular mycorrhizal fungus. New Phytol., 95, 381-396.

Guzm’an-Guzm'an, P., Porras -Troncoso, M.D., Olmedo- Monfil, V., Herrera-Estrella, A., (2018). Trichoderma Species: Versatile Plant Symbionts. The American Phytopathological Society, 1-11.

Hohmann, P., Jones, E. E., Hill, R. A., and Stewart, A. (2011). Understanding Trichoderma in the root system of Pinus radiata: associations betweenrhizosphere colonisation and growth promotion for commercially grownseedlings. Fungal Biol. 115, 759-767. doi: 10.1016/j.funbio.2011.05.010

Johansen, A., Finlay, R.D., Olsson, P.A., (1996). Nitrogen metabolism of the external hyphae of the arbuscular mycorrhizal fungus Glomusintraradices. New Phytol., 133, 705-712.

Karasu, A.M., Bayram, G, Turgut, I., (2009). The effect of nitrogen levels on forage yield and some attributes in some hybrid corn (ZeamaysindentataSturt.) cultivars sown as second crop for silage. African Journal of Agricultural Research., 4, 166-70.

Louarn, J., Carbonne, F., Delavault, P., Becard, G., Rochage., (2012). Redused germination of Orobanchecumana seeds in the presence of arbuscular mycorrhizal fungi or their exudates Plosa ONE 7:e49273. doi: 10,1371/journal.pone.0049273.

Ueno, K., Nomura, S., Muranaka, S., Mizutani, M., Takikawa, H., Sugimoto, Y., (2011). Ent-20epi-orobanchol and its acetate, as germination stimulants for Strigagesnerioides seeds isolated from cowpea and red clover. J. Agric. Food Chem., 59, 10485-10490.

Vinale, F., Sivasithamparam, K., Ghisalberti, E.L., Marra, R., Woo, S.L., Lorito, M., (2008) Trichoderma-plant- pathogen interactions. Soil Biol. Biochem., 40, 1-10. 